\title{
CLAE-PI aplicada ao doseamento de vitaminas do complexo B em misturas: fundamentação e validação de método
}

\author{
Eliane Maria Donato, Ângelo Ricardo Zanotto, Ana Maria Bergold*
}

Departamento de Produção de Matéria-prima, Faculdade de Farmácia, Universidade Federal do Rio Grande do Sul

*Correspondência:

A. M. Bergold

Departamento de Produção de Matériaprima

Faculdade de Farmácia - UFRGS

Av. Ipiranga, 2752

90610-000 - Porto Alegre/RS

E-mail: bergold@farmácia.ufrgs.br
Um método simples e rápido para determinação simultânea das vitaminas nicotinamida, tiamina, piridoxina, riboflavina e pantotenato de cálcio, em associação com minerais, foi desenvolvido por cromatografia líquida de alta eficiência, utilizando a técnica de pareamento ionico, coluna C-8 Perkin Elmer (150 5 4,6 $\mathrm{mm} \mathrm{DI}$, partícula $5 \mathrm{~mm}$, poro 80 A) e detector de ultravioleta $(210$ e $270 \mathrm{~nm})$. A fase móvel composta de água e metanol (894:106), contendo $10 \mathrm{mM}$ de hexanossulfonato de sódio, $0,5 \%$ de ácido acético e $0,1 \%$ de trietilamina a pH 3,5 promoveu excelente separação das vitaminas. O método foi aplicado com sucesso à forma farmacêutica de comprimidos e drágeas, contendo também minerais. Linearidade, precisão, recuperação e especificidade foram satisfatórias. A taxa de recuperação do método foi de $98 \%$ a $102 \%$ e os desvios padrão relativos encontrados variaram entre 0,9 e 2,5\%.
Unitermos:

- Controle de qualidade

- Vitaminas hidrossolúveis

- Doseamento CLAE

\section{INTRODUÇÃO}

Associações de vitaminas do complexo B estão sendo cada vez mais utilizadas como medicamentos, principalmente na forma de comprimidos, drágeas e cápsulas, normalmente combinadas com minerais. O uso difundido dessas preparações multivitamínicas tem estimulado a procura por métodos mais rápidos e específicos para quantificá-las.

Por outro lado, a determinação das vitaminas do complexo B em associação têm sido um grande problema para os profissionais do controle de qualidade, tendo em vista a instabilidade desses compostos, a complexidade das matrizes nas quais são usualmente encontradas e a falta de metodologia rápida, específica e de baixo custo, para a determinação quantitativa ao alcance da maioria dos laboratórios.
Os métodos farmacopéicos propostos para a quantificação dessas vitaminas incluem cromatografia líquida de alta eficiência (CLAE) com variantes de acessórios, espectrofotometria e microbiologia. Demais métodos encontrados na revisão bibliográfica para determinação simultânea de vitaminas hidrossolúveis utilizando detector de ultravioleta não incluem a determinação do pantotenato de cálcio (Dong et al., 1988; Nhur, Phi, 1993; Li, 2002), aumentando conseqüentemente o tempo e o custo das análises. Li e Chen (2001) incluiram a determinação do pantotenato em misturas multivitamínicas, por CLAE, porém, com a utilização de detector de arranjo de diodos.

O presente trabalho buscou determinar simultaneamente as vitaminas nicotinamida, piridoxina, tiamina, riboflavina e pantotenato de cálcio, em associação com minerais, em duas formulações comumente encontradas 
no mercado, por CLAE, utilizando a técnica de pareamento iônico (CLAE-PI) e detector de ultravioleta.

\section{MATERIAL E MÉTODOS}

\section{Material}

\section{Reagentes e soluções}

Para a preparação da fase móvel e do diluente foram utilizados metanol e acetonitrila grau CLAE (OMNISOLV), hexanossulfonato de sódio grau CLAE (ACROS) e água purificada através de sistema Milli-Q PLUS (Millipore ${ }^{\circledR}$ ). Os demais reagentes utilizados foram de grau analítico: ácido acético glacial, trietilamina, ácido fosfórico e edetato dissódico. A solução de diluição (SD) foi constituída de edetato dissódico 2,5\% (p/v) em água, acetonitrila e ácido acético glacial $(940: 50: 10 \mathrm{v} / \mathrm{v})$. Como fase móvel utilizou-se água e metanol (894:106) contendo $10 \mathrm{~m} M$ de hexanossulfonato de sódio, $0,5 \%$ de ácido acético glacial e $0,1 \%$ de trietilamina. A fase móvel foi preparada dissolvendo-se $1,88 \mathrm{~g}$ de hexanossulfonato de sódio, em 1 litro de água, adicionada de $5 \mathrm{~mL}$ de ácido acético glacial e $1 \mathrm{~mL}$ de trietilamina. $\mathrm{O} \mathrm{pH}$ foi ajustado para 3,5 com ácido fosfórico 10 M; $894 \mathrm{~mL}$ dessa solução aquosa foram misturados com $106 \mathrm{~mL}$ de metanol.

\section{Equipamento}

Utilizou-se cromatógrafo Shimadzu LC-10AD VP, detector de UV-VIS SPD-10AV VP, central de controle SCL-10A VP e desgaseificador DGU-14A com injetor manual Rheodyne com loop de $20 \mu \mathrm{L}$. As vitaminas foram quantificadas em coluna C-8 Perkin Elmer ( 150 x 4,6 mm DI, com partícula de $5 \mathrm{~mm}$ e poro de $80 \AA$ ) e eluídas em sistema isocrático, com gradiente de vazão: de 0,01 a 10 minutos: $1,2 \mathrm{~mL} / \mathrm{min}$; aos 12 minutos: $1,8 \mathrm{~mL} / \mathrm{min}$ e dos 12 aos 40 minutos: $1,8 \mathrm{~mL} / \mathrm{min}$. Nicotinamida, cloridrato de piridoxina, cloridrato de tiamina e riboflavina foram detectadas no comprimento de onda de $270 \mathrm{~nm}$ enquanto que o pantotenato de cálcio foi detectado a $210 \mathrm{~nm}$.

\section{Métodos}

\section{Amostras}

A metodologia desenvolvida por CLAE-PI foi aplicada à determinação simultânea de duas formulações multivitamínicas (a) comprimidos revestidos (Vita 1) contendo $50 \mathrm{mg}$ de nicotinamida, $10 \mathrm{mg}$ de cloridrato de piridoxina, $15 \mathrm{mg}$ de cloridrato de tiamina, $15 \mathrm{mg}$ de riboflavina, $23 \mathrm{mg}$ de pantotenato de cálcio, $150 \mathrm{mg}$ de biotina, $10 \mathrm{mg}$ de cianocobalamina, $500 \mathrm{mg}$ de ácido ascórbico, $100 \mathrm{mg}$ de cálcio e $100 \mathrm{mg}$ de magnésio e (b) drágeas contendo $10 \mathrm{mg}$ de nicotinamida, $4 \mathrm{mg}$ de cloridrato de piridoxina, $5 \mathrm{mg}$ de cloridrato de tiamina, 2,5 $\mathrm{mg}$ de riboflavina, $5 \mathrm{mg}$ de pantotenato de cálcio, $6 \mathrm{mg}$ de cianocobalamina, $50 \mathrm{mg}$ de ácido ascórbico, $2.500 \mathrm{UI}$ de retinol, $200 \mathrm{mg}$ de colecalciferol, $15 \mathrm{mg}$ de tocoferol, $25 \mathrm{mg}$ de ferro, $5 \mathrm{mg}$ de cálcio, $60 \mathrm{mg}$ de fósforo e $0,5 \mathrm{mg}$ de manganês (Vita 2).

\section{Preparação das amostras}

Após a determinação dos pesos médios, comprimidos e drágeas foram, respectivamente, triturados em gral de porcelana. Quantidade suficiente de Vita 1 foi pesada em tubo de ensaio e foram adicionados $25 \mathrm{~mL}$ da SD. Agitou-se o tubo de ensaio contendo a amostra em vórtex CERTOMAT durante 1 minuto e posteriormente o tubo foi colocado em banho-maria mantido a $65^{\circ} \mathrm{C}$ durante 5 minutos; repetiu-se o procedimento de agitação e aquecimento. Retirou-se a amostra do banho-maria e agitou-se novamente em vórtex, durante 1 minuto. A amostra foi resfriada à temperatura ambiente e filtrada através de papel filtro. Após diluição cada $\mathrm{mL}$ continha teoricamente $420,0 \mu \mathrm{g}$ de nicotinamida, $84,0 \mu \mathrm{g}$ de cloridrato de piridoxina, 126,0 $\mu \mathrm{g}$ de cloridrato de tiamina, $126,0 \mu \mathrm{g}$ de riboflavina e 193,0 $\mu \mathrm{g}$ de pantotenato de cálcio. Procedeuse de igual forma para Vita 2, entretanto, pesou-se quantidade suficiente para obter $300,0 \mu \mathrm{g} / \mathrm{mL}$ de nicotinamida, $120,0 \mu \mathrm{g} / \mathrm{mL}$ de cloridrato de piridoxina, $150,0 \mu \mathrm{g} / \mathrm{mL}$ de cloridrato de tiamina, $75,0 \mu \mathrm{g} / \mathrm{mL}$ de riboflavina e $150,0 \mu \mathrm{g} / \mathrm{mL}$ de pantotenato de cálcio. As amostras foram preparadas ao abrigo da luz.

\section{Soluções das substâncias químicas de referência (SQRS)}

Foram preparadas duas soluções contendo a mistura das SQRs em SD, nas concentrações de 420,0 $\mu \mathrm{g} / \mathrm{mL}$ de nicotinamida (Nico), 84,0 $\mathrm{g} / \mathrm{mL}$ de cloridrato de piridoxina (Piri), 126,0 $\mu \mathrm{g} / \mathrm{mL}$ de cloridrato de tiamina (Tiam), 126,0 $\mu \mathrm{g} / \mathrm{mL}$ de riboflavina (Ribo) e 193,0 $\mu \mathrm{g} / \mathrm{mL}$ de pantotenato de cálcio (PCa), denominada SQR para Vita 1 e solução contendo $300,0 \mu \mathrm{g} / \mathrm{mL}$ de nicotinamida, $120,0 \mu \mathrm{g} / \mathrm{mL}$ de cloridrato de piridoxina, $150,0 \mu \mathrm{g} / \mathrm{mL}$ de cloridrato de tiamina, $75,0 \mu \mathrm{g} / \mathrm{mL}$ de riboflavina e $150,0 \mu \mathrm{g} / \mathrm{mL}$ de pantotenato de cálcio, denominada de $\mathrm{SQR}$ para Vita 2. As soluções contendo a mistura das SQRs foram obtidas mediante aquecimento em banho-maria mantido a $65^{\circ} \mathrm{C}$ sobre placa aquecedora com agitação (MA 085 Marconi), durante 10 minutos, ao abrigo da luz.

\section{Linearidade e limite de quantificação}

Para cada vitamina, construiu-se uma curva padrão com cinco diferentes concentrações, repetida em três diferentes dias. As SQRs foram dissolvidas, individualmen- 
te, em SD, nos seguintes intervalos de concentração: nicotinamida 190,0 a $630,0 \mu \mathrm{g} / \mathrm{mL}$, cloridrato de piridoxina 30,0 a 190,0 $\mu \mathrm{g} / \mathrm{mL}$, cloridrato de tiamina 70,0 a $230,0 \mu \mathrm{g} / \mathrm{mL}$, riboflavina 60,0 a 200,0 $\mu \mathrm{g} / \mathrm{mL}$ e pantotenato de cálcio 130,0 a $330,0 \mu \mathrm{g} / \mathrm{mL}$. A SQR da riboflavina foi dissolvida mediante aquecimento em banho-maria a $90^{\circ} \mathrm{C}$ durante 10 minutos. A linearidade para cada vitamina foi verificada através do estudo de regressão linear e validada pela ANOVA. O limite de quantificação (LQ) para cada vitamina foi calculado segundo ANVISA (2003).

\section{Precisão e exatidão}

A precisão do método foi verificada nas amostras de Vita 1 e Vita 2, através de seis ensaios completos, com experimentos realizados em três diferentes dias. A exatidão foi avaliada através da adição de quantidades conhecidas das SQR na amostra de Vita 1, em três diferentes níveis de concentração com ensaios também realizados em três diferentes dias. A percentagem de recuperação foi calculada utilizando a equação da AOAC INTERNATIONAL (Association of Official Analytical Chemists International, 1990). As amostras foram preparadas conforme descrito em preparação das amostras.

\section{Especificidade}

A especificidade foi determinada nas amostras de Vita 1 e Vita 2, através da determinação da pureza total dos picos cromatográficos, utilizando o equipamento previamente descrito, porém com detector de arranjo de diodos (SPD-M10A VP).

\section{RESULTADOS E DISCUSSÃO}

A técnica de pareamento iônico é comumente utilizada para análise de substâncias muito solúveis em água, as quais não são retidas pela coluna de fase reversa ou para separação de compostos iônicos. Bases e ácidos orgânicos capazes de reagir com os íons da amostra e formar pares iônicos não dissociados, podem atuar como contra-íon ou regente de pareamento iônico.

A adição de um reagente de pareamento iônico, ou seja, um contra-íon de carga oposta a da amostra a ser analisada, na fase móvel, formará "complexos" mais ou menos polares que o composto original alterando significativamente o tempo de retenção do composto iônico. Esta técnica permite separação relativamente rápida de mistura de compostos, em uma única corrida cromatográfica, sem prévio tratamento ou derivatização da amostra (Szepesi, 1990).

Os reagentes de pareamento iônico normalmente utilizados para o doseamento de complexos vitamínicos nos quais a piridoxina e a tiamina estão incluídas, são os da série dos sulfonatos, na forma de sal sódico, como o hexano, heptano e octanossulfonato de sódio. Optou-se pela utilização do hexanossulfonato de sódio como reagente de pareamento iônico, por ser o mais utilizado, segundo a literatura (Dong et al., 1988; Ivanovic et al., 1999; Li, 2002; USP 26).

Os melhores resultados para a determinação das vitaminas em Vita 1 e Vita 2 foram obtidos utilizando fase móvel constituída de água-metanol (894:106) contendo 10 $\mathrm{m} M$ de hexanossulfonato de sódio, $0,5 \%$ de ácido acético glacial e 0,1 de trietilamina em $\mathrm{pH} 3,5$. As vitaminas nicotinamida, cloridrato de piridoxina, cloridrato de tiamina, riboflavina e pantotenato de cálcio foram analisadas simultaneamente nessas amostras, com exatidão, precisão, linearidade e especificidade. Estas vitaminas, com exceção do pantotenato de cálcio, foram detectadas em $270 \mathrm{~nm}$, enquanto que o pantotenato de cálcio, devido à sua baixa absortividade molar, foi detectado em $210 \mathrm{~nm}$, em que as demais vitaminas também absorvem, mas com menor intensidade, com exceção da nicotinamida.

A formação de pares iônicos dos cátions tiamina e piridoxina com o hexanossulfonato de sódio em $\mathrm{pH}$ ácido aumentou consideravelmente o tempo de retenção desses compostos, permitindo, assim, a separação cromatográfica. Baseado no modelo referido por Watson (1999) para a interação da epinefrina com um reagente de pareamento iônico, a Figura 1 mostra a interação da piridoxina com o hexanossulfonato de sódio, utilizando a metodologia desenvolvida.

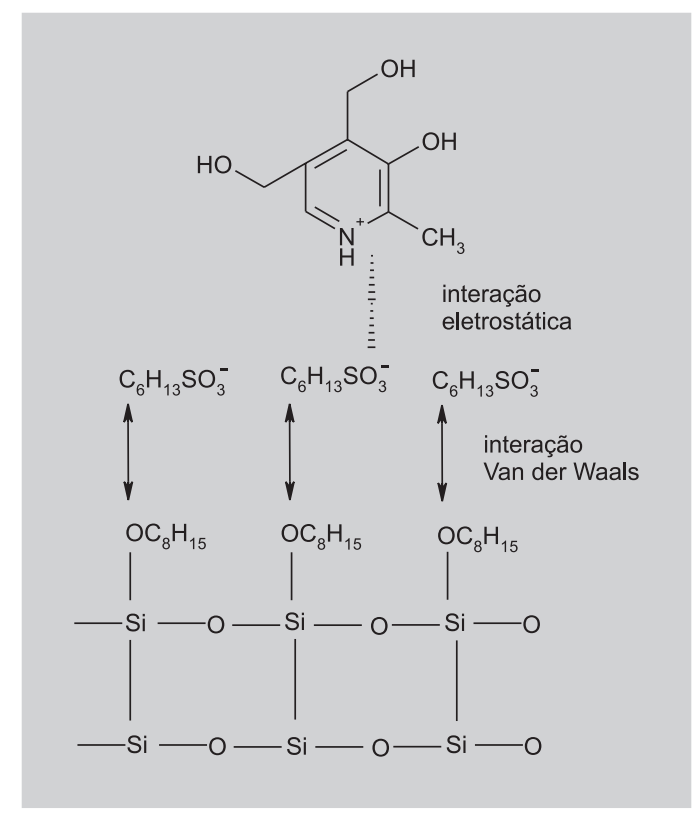

FIGURA 1 - Interação do cloridrato de piridoxina com o reagente de pareamento iônico hexanossulfonato de sódio, na superfície da coluna C-8 (adaptado do modelo de Watson (1999) para a epinefrina. 
O controle do pH em CLAE-PI fase reversa é um parâmetro essencial, pois com ele se controla o grau de ionização da amostra e com isso o tempo de retenção do composto. Segundo Szepesi (1990), como regra geral, maiores tempos de retenção podem ser obtidos no pH em que ocorre total ionização do soluto.

A separação dos picos do pantotenato de cálcio e da nicotinamida em $210 \mathrm{~nm}$ foi obtida com aumento do $\mathrm{pH}$ de 3,0 para 3,5. Entretanto, neste $\mathrm{pH}$ fez-se necessário aumentar a concentração do hexanossulfonato de sódio de 8 para $10 \mathrm{mM}$, devido à diminuição da formação dos pares iônicos pela diminuição da ionização dos compostos bási$\cos$ (piridoxina e tiamina). $\mathrm{O}$ efeito mais importante registrado com o aumento de 0,5 unidades de $\mathrm{pH}$ foi verificado na redução do tempo de retenção da tiamina. O efeito sobre o tempo de retenção da piridoxina foi menos pronunciado, conforme também observado por Dong e colaboradores (2001).

O metanol foi utilizado como modificador orgânico, baseado em estudos realizados por Dong e colaboradores (2001) para determinação de vitaminas hidrossolúveis por CLAE-PI. Segundo os pesquisadores, com metanol, foram obtidos os melhores resultados, quando comparados com os da acetonitrila e do tetraidrofurano. O ácido acético glacial foi utilizado para acidificar a fase móvel, visando a facilitar a formação de pares iônicos das vitaminas básicas com o contra-íon.

A trietilamina foi utilizada na fase móvel, para reduzir o fator de cauda dos solutos básicos, causado pela interação desses compostos com os grupos silanóis livres na superfície da coluna C-8 (Figura 2).

O uso do EDTA como parte da SD objetivou quelar os minerais presentes na amostra, evitando sua interferên-

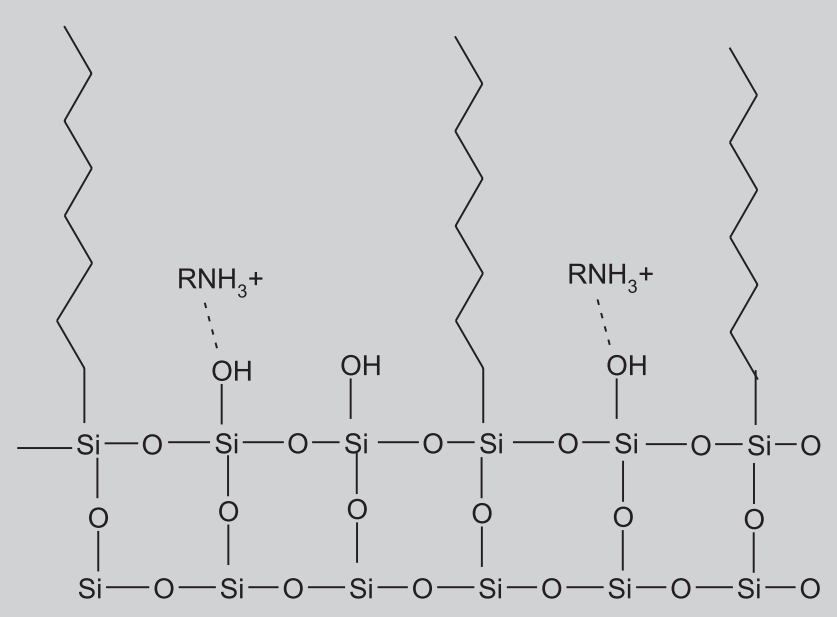

FIGURA 2 - Interação de aminas com grupos silanóis livres na superfície da coluna C-8 (Watson, 1999). cia na análise. Utilizou-se a concentração de 2,5\% preconizada pela Farmacopéia Americana (USP 26).

O gradiente de fluxo da fase móvel permitiu a diminuição do tempo de análise. As soluções depois de preparadas apresentam estabilidade de aproximadamente três horas. Após este período, pode não haver mais reprodutibilidade nos resultados. Para formulações semelhantes, utilizando CLAE, a Farmacopéia Americana (USP 26) preconiza tempo de três horas, no máximo, para a realização da análise. Os cromatogramas das SQRs e das amostras de Vita 1 e Vita 2 podem ser visualizados nas Figuras 3, 4 e 5, respectivamente.

Nas amostras comerciais analisadas encontram-se além dos minerais, outras vitaminas; entretanto, nenhum pico referente a estes foi detectado neste sistema cromatográfico. Formulações em que a riboflavina-5fosfato esteja presente, principalmente em formas farmacêuticas líquidas, ocorre a co-eluição dos picos das demais vitaminas com os compostos relacionados a ela. Como pode ser observado na Figura 6, a piridoxinia co-elui com a riboflavina-5-fosfato e composto a ela relacionado. A nicotinamida também sofre interferência de composto relacionado à riboflavina-5-fosfato.

O intervalo de linearidade do método para cada vitamina foi determinado de forma a contemplar os limites inferiores e superiores preconizados pela Farmacopéia Americana (USP 26), ou seja, de $90,0 \%$ a $150,0 \%$, e pode ser visualizado na Tabela I, juntamente com o limite de quantificação (LQ). Coeficiente de correlação acima de 0,9997 foi obtido para todas as vitaminas $(\mathrm{p}<0,05)$.

A precisão intermediária foi avalida através do desvio padrão relativo (DPR) interdia, em três diferentes dias, distribuídos no período de um mês e a repetibilidade pela avaliação dos DPR obtidos intradias. Os resultados obtidos demonstram que o método CLAE-PI desenvolvido é preciso, tendo em vista que os DPRs interdia (Tabela II) e intradia (não apresentados) foram inferiores a 2,0\%.

Para avaliar a exatidão do método, foram adicionadas quantidades de SQRs na amostra de Vita 1 de forma a obter amostras fortificadas (AF) contendo 85\% $\left(\mathrm{AF}_{1}\right)$, $107 \%\left(\mathrm{AF}_{2}\right)$ e $143 \%\left(\mathrm{AF}_{3}\right)$ da concentração de trabalho para cada vitamina, com experimentos realizados em três diferentes dias. Os percentuais médios de recuperação obtidos (Tabela III) foram satisfatórios para todas as vitaminas, demonstrando que o método CLAE-PI desenvolvido mostrou-se exato para Vita 1. Pode-se inferir que o método utilizado é exato também para Vita 2, visto que os parâmetros de precisão, linearidade e especificidade foram estabelecidos (ICH, 1996).

A especificidade de um método analítico dentre outras formas pode ser avaliada através da determinação 

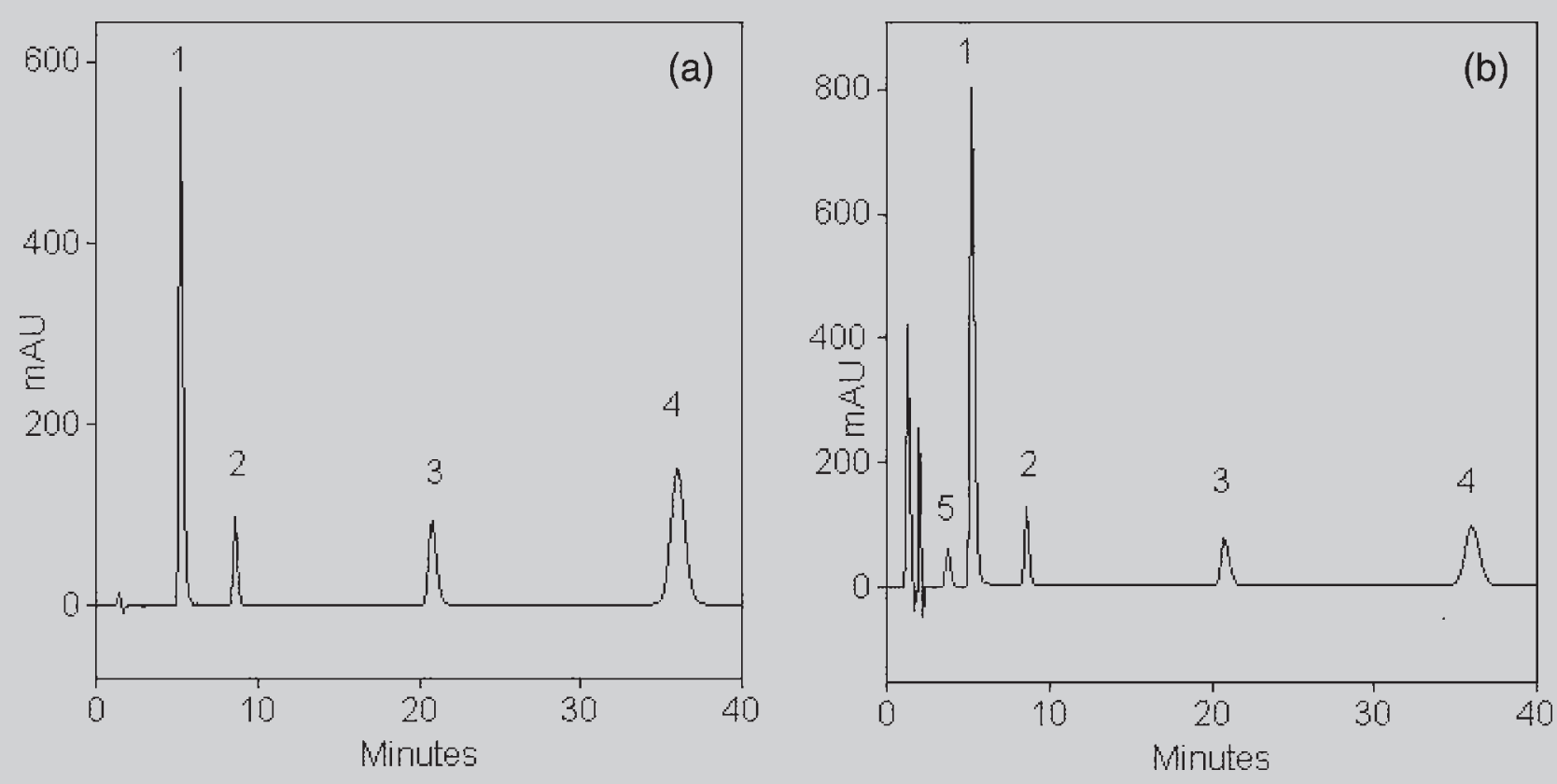

FIGURA 3 - Cromatogramas das SQRs: (1) nicotinamida 420,0 $\mu \mathrm{g} / \mathrm{mL}$, (2) cloridrato de piridoxina $84,0 \mu \mathrm{g} / \mathrm{mL}$, (3) cloridrato de tiamina $126,0 \mu \mathrm{g} / \mathrm{mL}$, (4) riboflavina $126,0 \mu \mathrm{g} / \mathrm{mL}$ e (5) pantotenato de cálcio 193,0 $\mu \mathrm{g} / \mathrm{mL}$, obtidos por CLAEPI, utilizando coluna C-8 (150 x 4,6 mm DI, 5 mm, 80 A, Perkin Elmer) e fase móvel constituída de água e metanol (894:106) contendo $10 \mathrm{~m} M$ de hexanossulfonato de sódio, $0,5 \%$ de ácido acético glacial e $0,1 \%$ de trietilamina, determinados a $270 \mathrm{~nm}$ (a) e em $210 \mathrm{~nm}$ (b) visando à quantificação do pantotenato de cálcio.
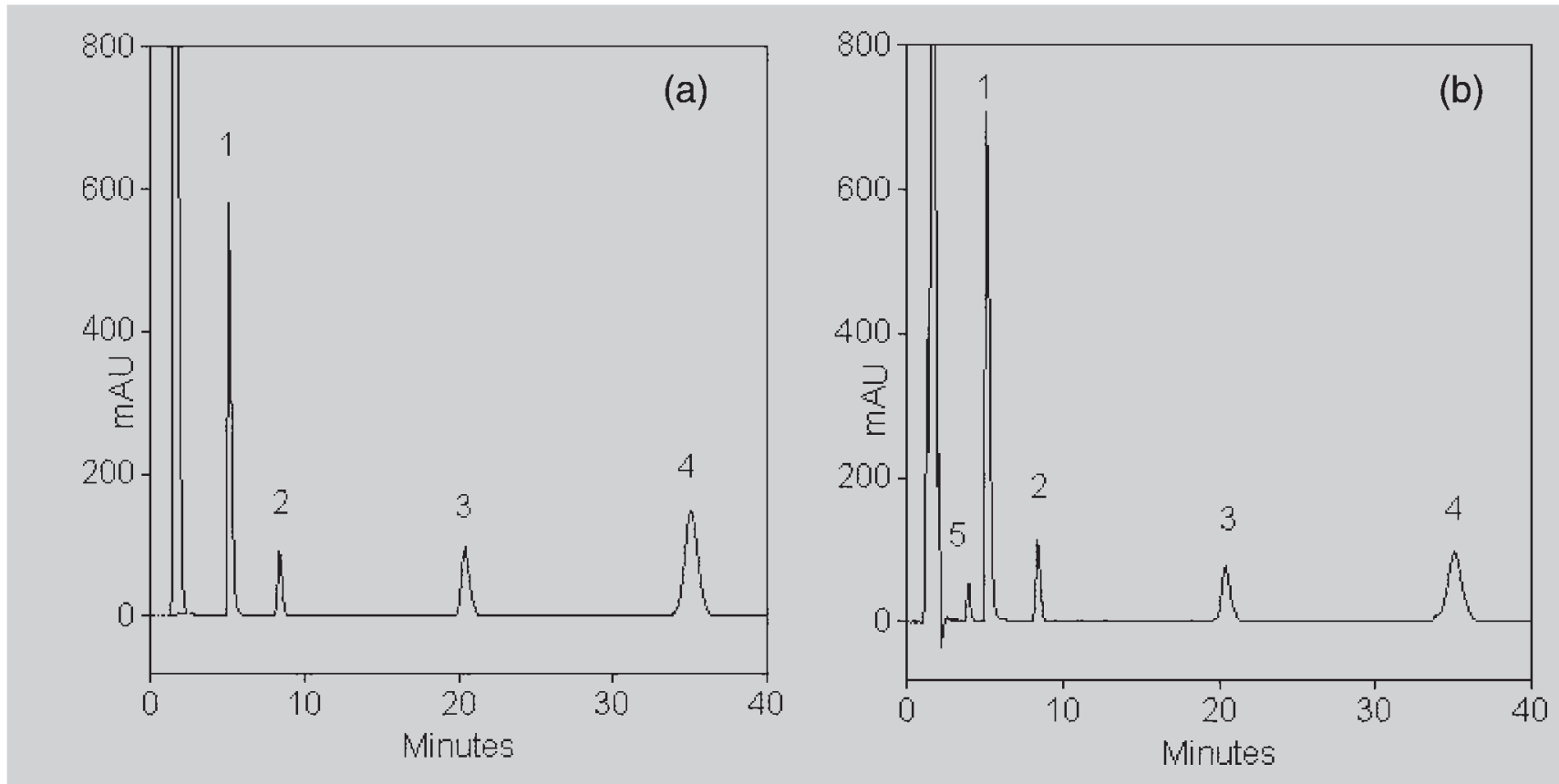

FIGURA 4 - Cromatogramas de Vita 1: (1) nicotinamida 420,0 $\mu \mathrm{g} / \mathrm{mL},(2)$ cloridrato de piridoxina 84,0 $\mu \mathrm{g} / \mathrm{mL}$, (3) cloridrato de tiamina $126,0 \mu \mathrm{g} / \mathrm{mL}$, (4) riboflavina $126,0 \mu \mathrm{g} / \mathrm{mL}$ e (5) pantotenato de cálcio 193,0 $\mu \mathrm{g} / \mathrm{mL}$, obtidos por CLAE-PI, utilizando coluna C-8 (150 x 4,6 mm DI, 5 mm, 80 Å, Perkin Elmer) e fase móvel constituída de água e metanol (894:106) contendo $10 \mathrm{~m} M$ de hexanossulfonato de sódio, $0,5 \%$ de ácido acético glacial e $0,1 \%$ de trietilamina, determinados a 270 $\mathrm{nm}$ (a) e em $210 \mathrm{~nm}$ (b) visando à quantificação do pantotenato de cálcio. 

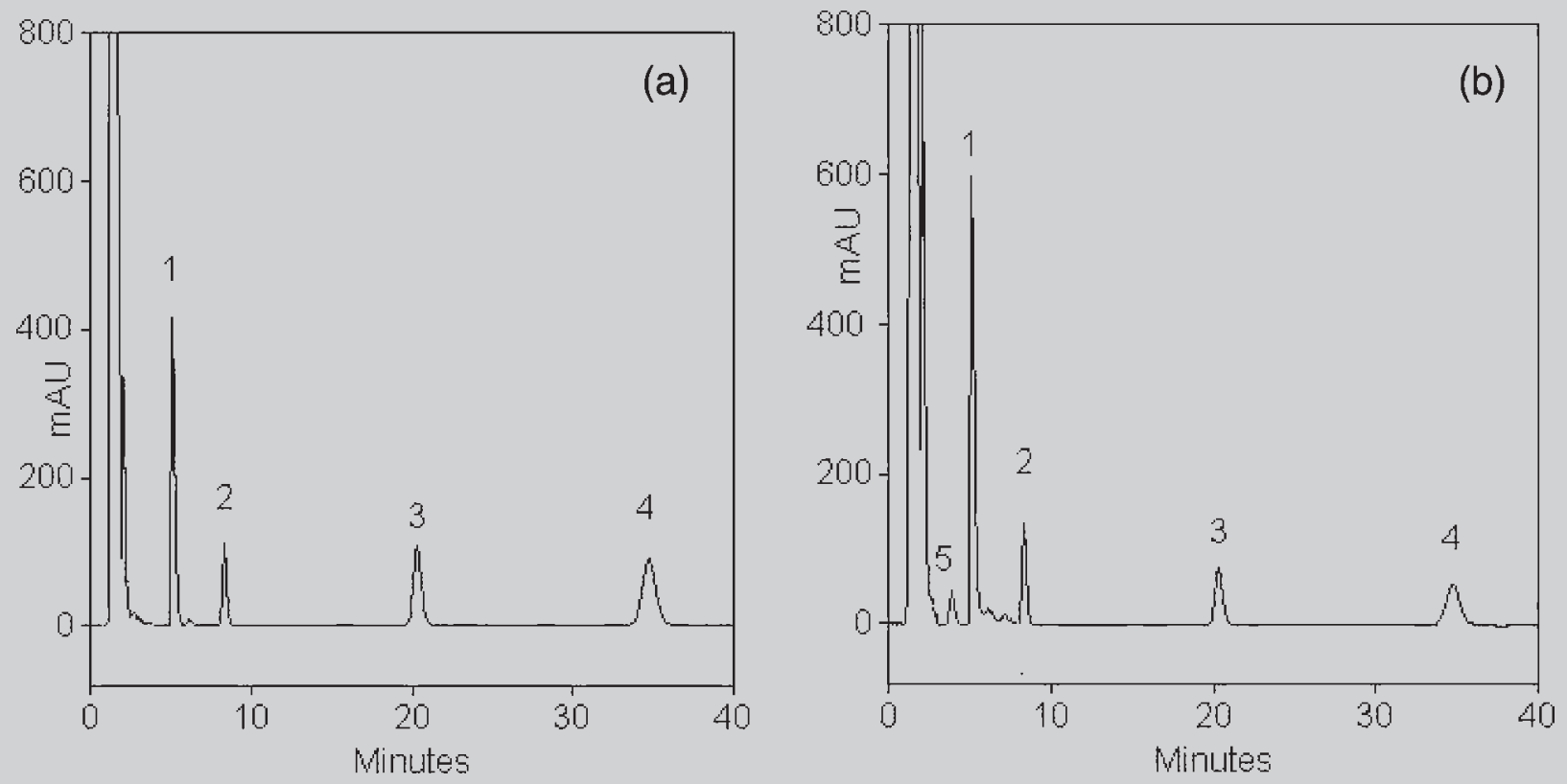

FIGURA 5 - Cromatogramas de Vita 2: (1) nicotinamida 300,0 $\mu \mathrm{g} / \mathrm{mL}$, (2) cloridrato de piridoxina 120,0 $\mu \mathrm{g} / \mathrm{mL},(3)$ cloridrato de tiamina $150,0 \mu \mathrm{g} / \mathrm{mL}$, (4) riboflavina $75,0 \mu \mathrm{g} / \mathrm{mL}$ e (5) pantotenato de cálcio $150,0 \mu \mathrm{g} / \mathrm{mL}$, obtidos por CLAEPI , utilizando coluna C-8 (150 x 4,6 mm DI, 5 mm, 80 A, Perkin Elmer) e fase móvel constituída de água e metanol (894:106) contendo $10 \mathrm{~m} M$ de hexanossulfonato de sódio, 0,5\% de ácido acético glacial e $0,1 \%$ de trietilamina, determinados a $270 \mathrm{~nm}$ (a) e em $210 \mathrm{~nm}$ (b) visando à quantificação do pantotenato de cálcio.

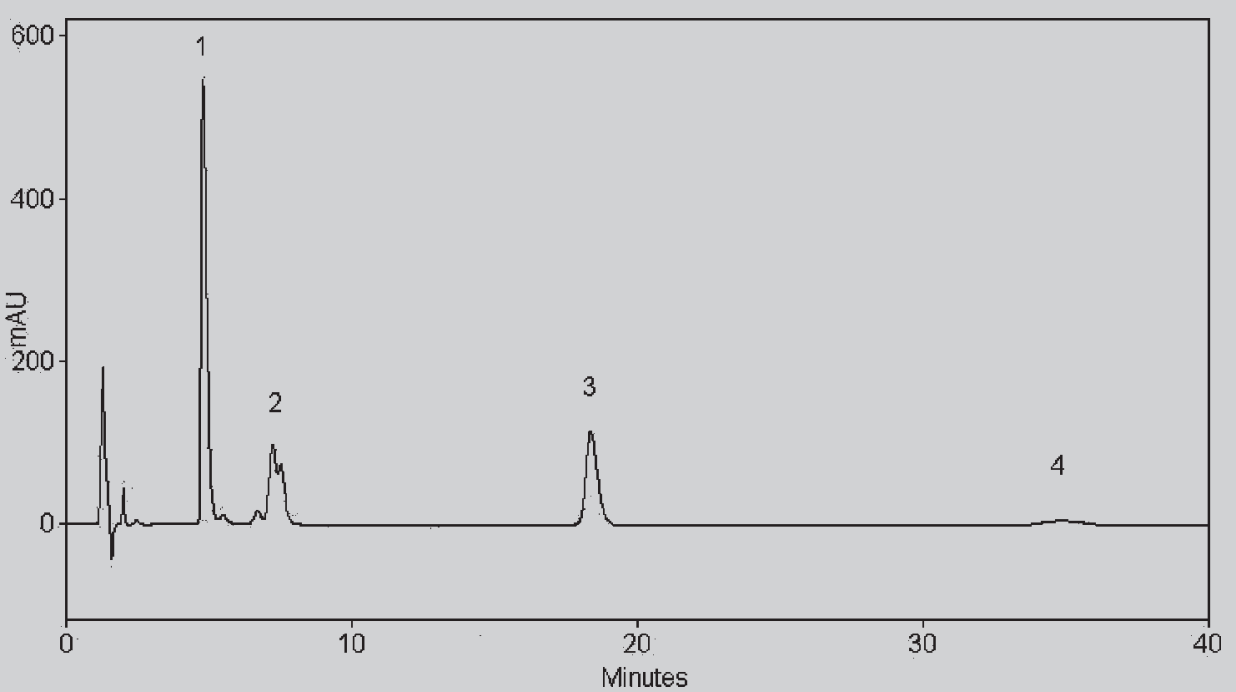

FIGURA 6 - Cromatograma das SQRs: (1) nicotinamida 370,0 $\mu \mathrm{g} / \mathrm{mL}$ + composto relacionado à riboflavina-5-fosfato, (2) riboflavina-5-fosfato $85,0 \mu \mathrm{g} / \mathrm{mL}$ + cloridrato de piridoxina $85,0 \mu \mathrm{g} / \mathrm{mL}+$ composto relacionado à riboflavina-5-fosfato, (3) cloridrato de tiamina $150,0 \mu \mathrm{g} / \mathrm{mL}$ e (4) riboflavina base, obtidos por CLAE-PI a $270 \mathrm{~nm}$, utilizando coluna C-8 (150 x 4,6 mm DI, $5 \mathrm{~mm}, 80 \AA$, Perkin Elmer) e fase móvel constituída de água e metanol (894:106) contendo $10 \mathrm{~m} M$ de hexanossulfonato de sódio, $0,5 \%$ de ácido acético glacial e $0,1 \%$ de trietilamina. 
TABELA I - Intervalo de concentração linear, equação da reta, coeficiente de correlação, desvios padrão e o LQ para cada vitamina, obtidos durante a realização das curvas padrão pelo método CLAE-PI

\begin{tabular}{lclrrrr}
\hline Vitamina & Intervalo linear $(\boldsymbol{\mu g} / \mathbf{m L})$ & \multicolumn{1}{c}{$\mathbf{y}=\mathbf{a x}+\mathbf{b}$} & $\mathbf{r}$ & $\mathbf{D a}$ & $\mathbf{D b}$ & $\mathbf{L Q}(\boldsymbol{\mu g} \mathbf{m L})$ \\
\hline Nico & 190,0 a 630,0 & $\mathrm{y}=19112 \mathrm{x}+43517$ & 0,99995 & 37570 & 140 & 19,7 \\
Piri & 30,0 a 190,0 & $\mathrm{y}=10342 \mathrm{x}-5030$ & 0,99995 & 1381 & 41 & 1,3 \\
Tiam & $70,0 \mathrm{a} 230,0$ & $\mathrm{y}=19435 \mathrm{x}+1964$ & 0,99999 & 10156 & 97 & 5,2 \\
Ribo & 60,0 a 200,0 & $\mathrm{y}=54087 \mathrm{x}-16759$ & 0,99970 & 64555 & 964 & 11,9 \\
Pca & $130,0 \mathrm{a} 330,0$ & $\mathrm{y}=1200 \mathrm{x}-2596$ & 0,99998 & 2693 & 13 & 22,4 \\
\hline
\end{tabular}

(Da) desvio padrão do intercepto; (Db) desvio padrão da inclinação; (LQ) limite de quantificação

TABELA II - Valores experimentais obtidos na determinação da precisão intermediária do método para Vita 1 e Vita 2 , por CLAE-PI

\begin{tabular}{|c|c|c|c|c|c|c|c|c|}
\hline \multirow[b]{2}{*}{ Vitamina } & \multicolumn{4}{|c|}{ Vita 1} & \multicolumn{4}{|c|}{ Vita 2} \\
\hline & $\begin{array}{c}\mathrm{Ct} \\
\mu \mathrm{g} / \mathrm{mL}\end{array}$ & $\begin{array}{c}{ }^{*} \mathrm{Ce} \\
\mu \mathrm{g} / \mathrm{mL}\end{array}$ & $\begin{array}{c}\text { Teor } \\
\text { médio \% }\end{array}$ & $\begin{array}{c}\text { DPR } \\
\text { interdia }\end{array}$ & $\begin{array}{c}\mathbf{C t} \\
\mu \mathrm{g} / \mathrm{mL}\end{array}$ & $\begin{array}{c}{ }^{*} \mathrm{Ce} \\
\mu \mathrm{g} / \mathrm{mL}\end{array}$ & $\begin{array}{c}\text { Teor } \\
\text { médio \% }\end{array}$ & $\begin{array}{c}\text { DPR } \\
\text { interdia }\end{array}$ \\
\hline Nico & 420,0 & 451,0 & 107,4 & 0,74 & 300,0 & 293,5 & 97,9 & 0,88 \\
\hline Piri & 84,0 & 84,3 & 100,4 & 1,45 & 120,0 & 117,9 & 98,4 & 1,23 \\
\hline Tiam & 126,0 & 132,8 & 105,4 & 0,70 & 150,0 & 145,5 & 91,7 & 0,85 \\
\hline Ribo & 126,0 & 132,2 & 104,9 & 1,20 & 75,0 & 73,5 & 98,3 & 1,12 \\
\hline $\mathrm{PCa}$ & 193,0 & 202,6 & 105,0 & 0,89 & 150,0 & 148,0 & 98,6 & 1,39 \\
\hline
\end{tabular}

* cada valor corresponde à média de 18 ensaios completos; $(\mathrm{Ct})$ concentração teórica; $(\mathrm{Ce})$ concentração experimental.

TABELA III - Valores experimentais obtidos na determinação da exatidão do método para Vita 1, por CLAE-PI

\begin{tabular}{lccccc}
\hline Vitamina & Amostra & $\begin{array}{c}\text { Concentração } \\
\text { incorporada } \\
(\boldsymbol{\mu g} / \mathbf{m L})\end{array}$ & $\begin{array}{c}\text { Concentração média } \\
\text { encontrada* } \\
(\boldsymbol{\mu g} / \mathbf{m L})\end{array}$ & $\begin{array}{c}\text { Recuperação } \\
\mathbf{( \% )}\end{array}$ & DPR \\
\hline Nicotinamida & ${ }^{1} \mathrm{AF}_{1}$ & 60,0 & 60,2 & 100,4 & 1,82 \\
& ${ }^{2} \mathrm{AF}_{2}$ & 150,0 & 147,9 & 98,6 & 2,16 \\
Cloridrato de & ${ }^{3} \mathrm{AF}_{3}$ & 300,0 & 294,0 & 98,0 & 1,89 \\
piridoxina & $\mathrm{AF}_{1}$ & 12,0 & 12,1 & 100,5 & 0,91 \\
& $\mathrm{AF}_{2}$ & 30,0 & 30,0 & 99,9 & 1,33 \\
Cloridrato de & $\mathrm{AF}_{3}$ & 60,0 & 59,7 & 99,5 & 0,85 \\
tiamina & $\mathrm{AF}_{1}$ & 18,0 & 17,7 & 98,3 & 1,48 \\
& $\mathrm{AF}_{2}$ & 45,0 & 45,2 & 100,4 & 1,82 \\
Riboflavina & $\mathrm{AF}_{3}$ & 90,0 & 91,3 & 101,5 & 2,54 \\
Pantotenato & $\mathrm{AF}_{1}$ & 18,0 & 18,3 & 101,7 & 0,46 \\
de cálcio & $\mathrm{AF}_{2}$ & 45,0 & 45,1 & 100,3 & 1,91 \\
& $\mathrm{AF}_{3}$ & 90,0 & 91,7 & 99,6 & 2,40 \\
& $\mathrm{AF}_{1}$ & 28,0 & 27,9 & 100,2 & 2,20 \\
& $\mathrm{AF}_{2}$ & 70,0 & 70,1 & 99,9 & 2,24 \\
\hline
\end{tabular}

* cada valor refere-se à media de três amostras analisadas em três diferentes dias. ${ }^{1}$ determinado simultaneamente com as demais $\mathrm{AF}_{1} ;{ }^{2}$ determinado simultaneamente com as demais $\mathrm{AF}_{2} ;{ }^{3}$ determinado simultaneamente com as demais $\mathrm{AF}_{3}$. 
da pureza do pico cromatográfico, utilizando detector de arranjo de diodos (ANVISA, 2003), o qual mostra gráfica e numericamente a similaridade do espectro do pico da substância de interesse. Os resultados obtidos (Tabela IV) indicam que o pico das vitaminas nicotinamida, cloridrato de piridoxina, cloridrato de tiamina, riboflavina e pantotenato de cálcio de Vita 1 e Vita 2 são considerados similares, ou seja, o pico cromatográfico refere-se à substância de interesse, sem interferentes.

TABELA IV - Índice de pureza do pico cromatográfico para nicotinamida, cloridrato de piridoxina, cloridrato de tiamina, riboflavina e pantotenato de cálcio*

\begin{tabular}{lcc}
\hline Vitamina & $\begin{array}{c}\text { ÍNDICE DE PUREZA DO PICO } \\
\text { Vita 1 }\end{array}$ \\
\hline Nico & 0,999994 & 0,999995 \\
Piri & 0,999998 & 0,999999 \\
Tiam & 0,999997 & 0,999996 \\
Ribo & 0,999998 & 0,999998 \\
PCa & 0,999908 & 0,999946 \\
\hline
\end{tabular}

* Determinados em Vita 1 e Vita 2, utilizando coluna C-8 (150 x 4,6 mm DI, 5 mm, 80 A, Perkin Elmer), detector de arranjo de diodos e fase móvel constituída de água e metanol (894:106) contendo $10 \mathrm{~m} M$ de hexanossulfonato de sódio, $0,5 \%$ de ácido acético glacial e $0,1 \%$ de trietilamina

O método desenvolvido por CLAE-PI para determinação simultânea de vitaminas hidrossolúveis em associação com minerais demonstrou ser perfeitamente aplicável para drágeas e comprimidos, podendo ser utilizado na rotina laboratorial. O uso do detector de ultravioleta coloca o método ao alcance da maioria dos laboratórios e a inclusão do pantotenato de cálcio reduz etapas e custos na análise das misturas.

\section{CONCLUSÕES}

O método desenvolvido e validado por CLAE-PI para o doseamento simultâneo das vitaminas nicotinamida, cloridrato de piridoxina, cloridrato de tiamina, riboflavina e pantotenato de cálcio demonstrou ser preciso, exato e específico, podendo ser utilizado na análise de complexos multivitamínicos em associação com minerais, na rotina de laboratórios.

O método não é aplicável à determinação dessas vitaminas, quando a riboflavina estiver presente na forma de riboflavina-5-fosfato, devido à co-eluição dos compostos relacionados a ela, com as demais vitaminas.
As amostras, em seguida à preparação para o doseamento, têm estabilidade de aproximadamente três horas. Após este tempo, não há mais reprodutibilidade dos resultados.

As vitaminas retinol, colecalciferol e tocoferol, cianocobalamina, biotina e ácido ascórbico, presentes nas amostras comerciais, não interferem na determinação simultânea da nicotinamida, cloridrato de piridoxina, cloridrato de tiamina, riboflavina e pantotenato de cálcio, nas condições descritas.

\section{ABSTRACT}

\section{Ion-pair HPLC applied to the assay of the vitamin $B$ group mixture: theorical bases and method validation}

A rapid and simple method for the simultaneous determination of nicotinamide, thiamine, pyridoxine, riboflavin and calcium pantothenate, associated with minerals was developed by high performance liquid chromatography. These vitamins were simultaneously assayed by reversed-phase ion-pair HPLC with $C-8$ column Perkin Elmer (150 $4.6 \mathrm{~mm}, 5 \mathrm{~mm}, 80$ A) and $U V$ detection (210 and $270 \mathrm{~nm}$ ). A mobile phase of water-methanol (894:106), $10 \mathrm{mM}$ hexanesulfonate, $0,5 \%$ acetic acid and 0,1\% triethylamine at $\mathrm{pH} 3.5$ allowed the most satisfactory separation of these vitamins. The method was successfully applied to the determination of vitamins in tablets and coated tablets. Linearity, precision, recovery and specificity were always satisfactory. The average recoveries were from $98 \%$ to $102 \%$ and the relative standard deviations were between 0.9 to $2.5 \%$.

UNITERMS: Quality control. Water-soluble vitamins. Assay HPLC.

\section{REFERÊNCIAS BIBLIOGRÁFICAS}

ANVISA: Brasil. Ministério da Saúde. Agência Nacional de Vigilância Sanitária. Resolução-RE n ${ }^{\circ}$ 899, 20.mai.2003., D.O.U., 02.jun.2003. Disponível em: $<\mathrm{http} / /$ www.anvisa.gov.br/legis/resol/2003/re/899 03re.htm>. Acesso em: 16 jun. 2003.

AOAC. Association of official Analytical Chemists. Official Methods of Analysis. 15.ed. Arlington, 1990. v.1, p. xvii.

DONG, M. W.; LEPORE J.; TARUMOTO T. Factors affecting the ion-pair chromatography of water-soluble vitamins. J. Chromatogr., v. 442, p. 81-95, 1988. 
ICH: Harmonised Tripartite Guideline. Validation of Analytical Procedures: Metodology, Q2B. In: INTERNATIONAL CONFERENCE ON HARMONISATION OF TECHNICAL REQUIREMENTS FOR REGISTRATION OF PHARMACEUTICALS FOR HUMAN USE, 1996. Disponível em: <http:// www.ich.org./ichq5.html\#Analytical $>$. Acesso em: 12 jun. 2002.

IVANOVIC, D.; POPOVIC, A.; RADULOVIC, D.; MEDENICA, M. Reversed-phase ion-pair HPLC determination of some water-soluble vitamins in pharmaceuticals. J. Pharm. Biomed. Anal., v. 18, n. 6, p. 999-1004, 1999.

LI, K. Simultaneous determination of nicotinamide, pyridoxine hydrochoride, thiamine mononitrate and riboflavin in multivitamin with minerals tablets by reversed-phase ionpair high performance liquid chromatography. Biomed. Chromatog., v. 16, n. 1, p. 504-507, 2002.

LI, H. B.; CHEN, F. Simultaneous determination of nine water-soluble vitamins in pharmaceutical preparations by high performance liquid chromatography with diode array detection. J. Sep. Sci, v. 24, p. 271-274, 2001.
NHUR, T. P. Q.; PHI, D. H. Simultaneous determination of hydrosoluble vitamins by HPLC method. Tap Chi Duoc Hoc. v. 5, p. 23-26, 1993.

SZEPESI, G. HPLC in pharmaceutical analysis. Boston: CRC Press, 1990. v.1, p. 49-65.

UNITED States Pharmacopoeia. 26 ed. Rockville: Unites States Phamacopoeial Convention, 2003. CD-ROM. (Nutritional Supplements $>$ Monographs $>$ Water-Soluble Vitamins p.1-13, Nutritional Supplements $>$ Monographs $>$ Oil-and Water-Soluble Vitamins p. 1-14).

WATSON, D. G. Pharmaceutical analysis. A textbook for pharmacy students and pharmaceutical chemists. Churchill Livingstone: London, 1999. p. 237-274,313-320; 195-204.

Recebido para publicação em 29 de dezembro de 2003. Aceito para publicação em 20 de agosto de 2004. 